\title{
The haptic Müller-Lyer illusion in sighted and blind people
}

\author{
Morton A Heller, Deneen D Brackett, Kathy Wilson, Keiko Yoneyama, Amanda Boyer, \\ Heather Steffen \\ Department of Psychology, Eastern Illinois University, Physical Sciences Building, Charleston, \\ IL 61920, USA; e-mail: cfmah1@eiu.edu \\ Received 10 January 2002, in revised form 3 July 2002, published online 16 August 2002
}

\begin{abstract}
We examined the effect of visual experience on the haptic Müller-Lyer illusion. Subjects made size estimates of raised lines by using a sliding haptic ruler. Independent groups of blindfolded-sighted, late-blind, congenitally blind, and low-vision subjects judged the sizes of wings-in and wings-out stimuli, plain lines, and lines with short vertical ends. An illusion was found, since the wings-in stimuli were judged as shorter than the wings-out patterns and all of the other stimuli. Subjects generally underestimated the lengths of lines. In a second experiment we found a nonsignificant difference between length judgments of raised lines as opposed to smooth wooden dowels. The strength of the haptic illusion depends upon the angles of the wings, with a much stronger illusion for more acute angles. The effect of visual status was nonsignificant, suggesting that spatial distortion in the haptic Müller-Lyer illusion does not depend upon visual imagery or visual experience.
\end{abstract}

\section{Introduction}

The purpose of this study was to evaluate the influence of visual experience and visual imagery on the haptic Müller-Lyer illusion. Judgments of extent in vision and touch may be altered by the presence of endings on a line (Coren and Girgus 1978; see Hatwell 1960). Thus, lines with 'wings-out' endings are typically judged as longer than lines with endings that point in the opposite direction. In the wings-out Müller-Lyer figure, the wings extend outward from the ends of a line (eg Coren and Girgus 1978). The present problem was to determine the strength of the illusion with raised-line drawings, and to ascertain if the illusion is influenced by visual experience.

Many researchers have assumed that illusions arise from perspective cues, mistaken impressions of depth (Fisher 1970), and from inappropriate constancy scaling (eg Gregory 1963). This explanation has been applied to the Ponzo and to the Müller-Lyer illusions. On the assumption that perception of extent is influenced by these processes, one might expect that haptics could differ from vision, for a variety of reasons.

Revesz (1950) argued that the space of the congenitally blind is vastly different from that of the sighted. For example, he thought that the blind are relatively insensitive to the vertical and horizontal spatial reference schemes (but see Heller et al 2001). Moreover, Revesz thought that sighted and late-blind people tend to visualize patterns that they touch, and this could influence touch. Late-blind people report that they recall how things look, and blindfolded-sighted subjects report that they generate visual images while touching objects (see Heller 2000a, 2000b; Heller and Schiff 1991). Similar arguments on visual imagery have been advanced by Axelrod and Cohen (1961). However, congenitally blind people must derive their understanding of spatial relations from haptics and audition.

The presence of the Müller-Lyer illusion in blind people was reported by Tsai (1967) and more recently by Casla et al (1999). However, our understanding of the illusion is incomplete. Tsai used small samples of blind subjects, and the report by Casla et al provided very few details about their methodology and did not report the strength of the illusion. Casla et al merely reported the frequency with which they 
found the Müller-Lyer illusion in nine congenitally blind subjects, one other blind subject with prior visual experience, and blindfolded-sighted participants. The visual Müller-Lyer illusion can vary in intensity (Dewar 1967), and one might expect that the same would apply to the haptic version of the illusion. Casla et al exposed each of their subjects to random sequences of stimuli that represented different forms and sizes of the Müller-Lyer illusion, the Ponzo illusion, the horizontal-vertical illusion, and a composite figure. This methodology further complicates any interpretation of their data, since responses to the various stimuli may not have been independent. Moreover, their subjects had a very limited number of trials with the Müller-Lyer illusion. Hatwell (1960) found the Müller-Lyer illusion in blind children. However, since there is a lag in the development of haptic space perception, it is not possible to generalize from data derived from children to adults.

Visual stimulation apparently influences the strength of the tactual Müller-Lyer illusion. Walker (1971) reported that the Müller-Lyer illusion was present in touch, and was altered by the presence of a visual array. Blindfolded-sighted subjects were exposed to tangible and visual blocks. The inducing array (the wings) was visible, but could not be felt. Nonetheless, subjects evidenced 'visual capture' and their perceptual judgments showed illusory misperception in a haptic version of the Müller-Lyer illusion.

The present study was designed to examine the influence of visual experience on the haptic Müller-Lyer illusion. Independent groups of blindfolded-sighted, late-blind, congenitally blind, and low-vision subjects were exposed to tangible raised-line versions of the Müller-Lyer figures. If visual experience and imagery influenced the expression of the Müller-Lyer illusion, then the congenitally blind subjects were expected to show a different pattern of results than the other subjects. The low-vision, late-blind, and blindfolded-sighted subjects were predicted to differ from the congenitally blind, since they all had the benefits of visual experience. It is unlikely that naive congenitally blind subjects would be sensitive to Müller-Lyer arrowheads as highly reduced perspective cues in raised-line pictures. According to Kennedy et al (1991), blind people can understand linear perspective, and thus might be sensitive to depth cues in raised-line pictures. However, one might expect that subjects with prior visual experience would generate visual images of the patterns that they feel. It was therefore reasonable to propose that these visual representations could influence the haptic Müller-Lyer illusion, perhaps by increasing its strength. Thus, there could be a number of visual or other sources of the illusion, only one of which involves perspective.

\section{Experiment 1: The haptic Müller-Lyer illusion in blindfolded-sighted and visually impaired people}

\subsection{Method}

2.1.1 Participants. There were forty subjects, including thirty visually impaired individuals. Table 1 provides details about educational level, gender, and other variables to provide the reader with information about the representativeness of the samples of visually impaired subjects. The subjects were recruited from central Illinois, mainly from Charleston, Champaign, Decatur, and Springfield. The ten congenitally blind subjects were blind since birth, or lost sight well before the end of the first year of life (mean age $=44.5$ years; SD, 10.4 years). The ten late-blind subjects lost sight after the first year of life (mean age $=49.1$ years; SD, 13.1 years). Additionally, ten subjects with very low vision were included in the study (mean age $=40.7$ years; SD, 16.4 years). Lowvision subjects were defined as those subjects with some light perception, some object perception, and, at most, very minimal pattern perception. The low-vision subjects could not see the raised lines that they felt. It should be noted that the majority of low-vision subjects described themselves as 'blind'. All of the subjects had minimal prior experience with tangible pictures, and were naïve to the purpose of this experiment. Five of 
Table 1. Characteristics of the blind subjects, including gender, age, education, age of onset, cause of blindness, and presence of light perception.

\begin{tabular}{llll}
\hline Gender Age/years Education & $\begin{array}{l}\text { Age of onset/ Cause } \\
\text { years }\end{array}$ & $\begin{array}{l}\text { Light } \\
\text { perception }\end{array}$
\end{tabular}

\section{Congenitally blind}

$\mathrm{M} \quad 46$

F $\quad 28$

F 37

F $\quad 46$

F 29

F 53

M 53

M 47

M 60

M 46

Late blind

F 57

$\mathrm{F} \quad 34$

M 54

M $\quad 65$

M $\quad 31$

M 57

M 28

F $\quad 58$

M 56

M 51

Low vision

F 22

M 24

F $\quad 43$

F $\quad 38$

M 63

F 41

F $\quad 69$

M 30

F 52

F 25
MA

HS

JD

HS

SG

HS

$\mathrm{SC}$

JD

SG

HS

$\begin{array}{lr}\text { SG } & 10 \\ \text { SC } & 7 \\ \text { PhD } & 43 \\ \text { PhD } & 29 \\ \text { SG } & 9 \\ \text { MA } & 2 \\ \text { SC } & 17 \\ \text { HS } & 2 \\ \text { BA } & 2 \\ \text { JD } & 5\end{array}$

$\begin{array}{ll}\text { SC } & \text { birth } \\ \text { SG } & 13 \\ \text { SC } & 23 \\ \text { MA } & 36 \\ \text { HS } & \text { birth } \\ & \\ \text { SG } & 15 \\ \text { GED } & 20 \\ \text { SC } & 8 \\ \text { HS } & \text { birth } \\ \text { SC } & \text { birth }\end{array}$

$\begin{array}{lc}\text { ROP } & \text { Yes } \\ \text { ROP } & \text { No } \\ \text { ROP } & \text { No } \\ \text { RLF } & \text { Yes } \\ \text { spinal meningitis } & \\ \text { RP, nystagmus, and } & \text { Yes } \\ \text { other unknown causes } & \\ \text { RP, nystagmus, and } & \text { Yes } \\ \quad \text { other unknown causes } & \\ \text { unknown } & \text { Yes } \\ \begin{array}{l}\text { ROP } \\ \text { congenital glaucoma, and } \\ \text { other unknown causes }\end{array} & \text { No } \\ \text { ROP } & \text { No }\end{array}$

RP

detached retina

virus

diabetes

optic nerve trauma

retinal blastoma

cataracts

spinal meningitis

retinal blastoma

cataracts/glaucoma

Yes

No

Yes

Yes

Yes

Yes

No

No

Yes

No

No

Yes

Yes

No

No

Yes

No

No

ROP Yes

RP Yes

RP Yes

RP Yes

congenital cataracts Yes

nystagmus; LV in one eye

diabetic retinopathy Yes (one eye)

macular degeneration Yes

hydrocephalus Yes

ROP, detached retina Yes

iritis, glaucoma,

detached retina

Note. F, female; M, male; LV, low vision; ROP, retinopathy of prematurity; RP, retinitis pigmentosa; SC, some college; SG, some graduate school; AS, junior college degree, BA, college degree; MA, Master of Arts degree; GED, high school equivalency diploma; HS, high school diploma; PhD, Doctor of Philosophy degree; JD, law degree.

the low-vision subjects said that they could see close hand motion, but only with very strong lighting and high contrast. The ten blindfolded-sighted subjects were recruited on the campus of Eastern Illinois University (mean age $=25.9$ years; SD, 8.8 years).

Two of the low-vision subjects said that they could see their hands on the table surface, but they did not look towards their hands while feeling the stimuli or the ruler. However, one of the late-blind subjects (totally blind and without light perception) said that he directed his gaze towards his hands during haptic tasks, since that helped him focus his attention on the stimuli. 
2.1.2 Stimuli and apparatus. The stimuli were produced with a Swedish raised-line drawing kit. The Swedish drawing kit produces a tangible, durable raised line when a ballpoint pen is used to draw over the surface (see Kennedy 1997). This drawing kit can be obtained from the Swedish agency for special education (SIH, Laromedel, Solna, Gardsvagen, S 169, 70 Solna, Sweden). The stimuli were tangible, raised horizontal lines measuring $2.5,5.2,7.6$, and $10.2 \mathrm{~cm}$. There were four line conditions in the experiment: a 'plain' line; a 'vertical ends' line with $1.4 \mathrm{~cm}$ vertical lines at the end of each horizontal segment; a 'wings-in' line, with arrow-shaped heads at each end of the horizontal lines (the lines comprising the arrowheads were $1.4 \mathrm{~cm}$ in length, and were at a $35^{\circ}$ angle from the horizontal, that is the included angle was $70^{\circ}$ ); the 'wings-out' line also had $1.4 \mathrm{~cm}$ arrowheads at a $35^{\circ}$ angle, but were inverted, with the tips of the arrowheads facing the lines (see figures 1a-1d). Note that the angle included by the arrows was $70^{\circ}$. The lines with vertical ends were included in the experiment to ensure that subjects could readily feel the ends of the lines, and to provide a comparison with the plain-lines condition. One reviewer commented that the $1.4 \mathrm{~cm}$ wings endings were not really comparable to $1.4 \mathrm{~cm}$ vertical-line endings since they did not always fit under a fingertip. However, the strength of the Müller-Lyer illusion depends upon the length of the wings, and $1.4 \mathrm{~cm}$ is a relatively small proportion of the longer stimuli. It was thought that $1.4 \mathrm{~cm}$ vertical-line endings would be sufficient to ensure that subjects could feel the ends of the lines in control conditions.

(a)

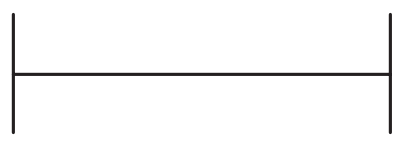

(b)
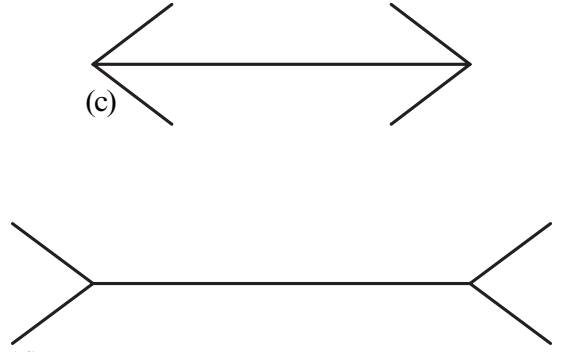

(d)

Figure 1. Stimuli in the experiment (a) plain line, (b) vertical-ends line, (c) 'wings-in' stimulus, (d) 'wings-out' stimulus.

A tangible sliding ruler was used to obtain line length judgments from subjects. The ruler could be adjusted by pushing it in or pulling it out from a panel (see figure 2). At the start of each trial, the ruler extended $1 \mathrm{~cm}$ from an opening in the panel $(21 \mathrm{~cm} \times 22.7 \mathrm{~cm})$. It was placed at the body midline, facing left, allowing subjects to use their left hands to pull the ruler out from the panel. Stimuli were attached to matte board and placed flat on the table surface, at the body midline. The tangible ruler was elevated upon a shelf, allowing the stimuli to be placed beneath it for tactual examination.

2.1.3 Design and procedure. The experiment took the form of a between - within design. Congenitally blind, late-blind, low-vision, and blindfolded-sighted subjects were exposed to all four types of stimuli: wings-in, wings-out, vertical ends, and plain lines (see figure 1), and repeated measures were taken on line size: $2.5,5.2,7.6$, and $10.2 \mathrm{~cm}$. Also, subjects performed two trials at each size, for a total of 32 judgments.

Subjects were asked to use their right index fingers to feel the lines, and were to use their left hands to pull out the ruler from the panel. This bimanual procedure was adopted to remove memory constraints and limitations from the task. Thus, the subjects were able to feel the lines and simultaneously indicate their size estimates. Participants were instructed to trace the lines with the index finger of their right hands to prevent them from using their fingers to 'measure' the raised lines, either with a 


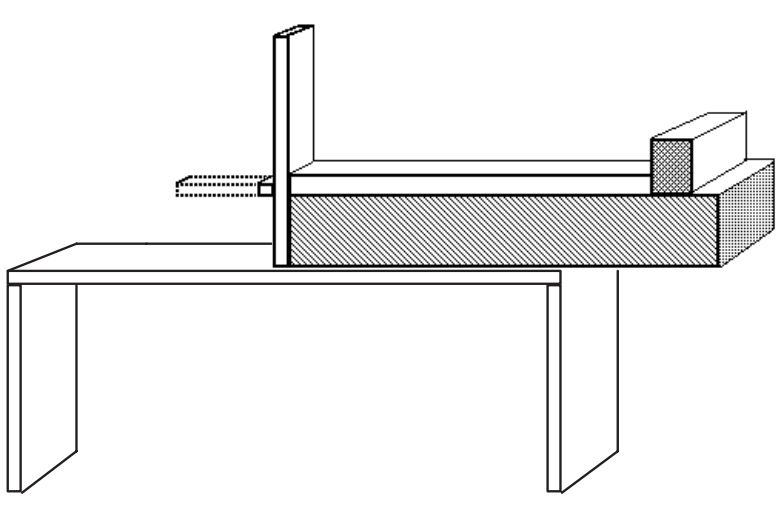

Figure 2. The haptic sliding ruler. The ruler was elevated upon a shelf, and the stimuli were placed beneath it. This allows the subjects to feel the stimulus with their right index fingers and make size estimates with their left hands.

pincers grasp, or by laying multiple fingers across an extent (see Heller et al 1999). Subjects were restricted to tracing forms with their right index fingers, but were permitted to manipulate the ruler in any fashion that they wished. However, they were instructed to only use the opposite hand for the ruler, and not use the hand with which they touched the stimuli.

The subjects were instructed to estimate the lengths of the lines, but they were told not to include the endings in their estimates. They were instructed to judge the lengths of the horizontal line, and were told to feel the ends as well. If a subject failed to feel a line ending and stopped short of the end of the line, s/he was reminded to feel the entire line. The subjects first felt the raised line, including the endings when appropriate, and then made their size estimate by adjusting the ruler with their left hands. If they wished, they were allowed to retrace the line and alter their size estimates.

Subjects started with either a 'wings' set of lines (wings-in and wings-out), or a set without wings (vertical ends and plain lines). Half of the subjects had the wings set first, followed by the lines without wings, and the other half had the opposite sequence. Within each set, the type of figure end was balanced. Half of the subjects started with the wings-in stimuli, and then had the wings-out (or vice versa); and in the non-wings lines, half had the vertical ends and then the plain lines (or vice versa). Half of the subjects were exposed to the stimuli in ascending-size order, and half of them had the stimuli in descending-size order. They had the reverse size order for the other type of line. Thus, if subjects had a descending-size order for the plain lines, they had an ascending-size order for the lines with vertical ends. This methodology was adopted to minimize the likelihood of the subjects groping for the stimuli, as might occur with randomization as the control method. Feedback was not given in any of the experiments reported here.

Note that this methodology involving the use of a tangible ruler permitted an assessment of the strength of the Müller-Lyer illusion and the presence of systematic size distortion with respect to an absolute standard, that is metric measure. Subjects were required to estimate the lengths of lines with a tangible ruler. In earlier research subjects were commonly required to divide a line comprised of wings-out and wings-in boundaries. Alternative methods required adjustment of a wings-in figure to match the size of a wings-out stimulus, or vice versa. With these other methods involving relative judgments, an overall bias in size estimates could be obscured by the methodology. For example, if subjects were to judge one side of an adjustment figure to be smaller than the other, they must then divide the line to increase the size of one 
side of the stimulus and reduce the other (eg Casla et al 1999). Similarly, if subjects were required to match the size of a wings-in figure to equal the perceived size of a wings-out figure, there would be no way of telling whether or not they misjudged the absolute sizes of both configurations.

\subsection{Results and discussion}

Table 2 summarizes the results of this experiment, and shows mean size judgments as a function of visual status and the configuration of the tangible lines. A 4 (visual status) $\times 4$ (figure) $\times 4$ (size) $\times 2$ (trials) analysis of variance (ANOVA) performed on the size-judgment data revealed a significant effect of figure (ie line ending) $\left(F_{3,108}=20.28, p<0.01\right)$. The data were consistent with the presence of a robust Müller-Lyer illusion in touch. For example, the wings-out figures were judged as about $50 \%$ longer than the wings-in figures for the shortest, $2.5 \mathrm{~cm}$ standards (see table 2). A Newman-Keuls test revealed that the wings-in figures $($ mean $=4.91 \mathrm{~cm}$ ) were judged as significantly shorter than all other figures, and the wings-out $($ mean $=5.99 \mathrm{~cm})$ figures were judged as significantly longer than all the other figures $(p<0.05)$. The lines with vertical ends and the plain lines were not significantly different from each other $(p>0.05)$. These results indicate that subjects could readily distinguish the ends of the plain lines, even without vertical-line endings. Note that subjects underestimated the sizes of all the figures, but underestimated the wings-out figures less than the other forms. The presence of the wings added to the subjects'

Table 2. Mean size judgments $(\mathrm{cm})$ for the Müller-Lyer illusion as a function of figure, visual status, and size (standard deviations in parentheses).

\begin{tabular}{|c|c|c|c|c|c|}
\hline \multirow[t]{2}{*}{ True size $/ \mathrm{cm}$} & \multicolumn{5}{|l|}{ Figure } \\
\hline & wings-in & wings-out & vertical ends & plain lines & overall \\
\hline \multicolumn{6}{|c|}{ Congenitally blind } \\
\hline 2.5 & $2.0(2.6)$ & $3.0(0.7)$ & $2.6(0.5)$ & $2.4(0.5)$ & $2.5(0.5)$ \\
\hline 5.1 & $4.0(1.2)$ & $5.0(1.3)$ & $4.6(1.0)$ & $4.4(0.8)$ & $4.5(0.9)$ \\
\hline 7.6 & $6.1(1.2)$ & $7.5(2.3)$ & $7.4(2.0)$ & $6.6(1.6)$ & $6.9(1.5)$ \\
\hline 10.2 & $8.3(1.7)$ & $9.9(2.6)$ & $9.7(2.9)$ & $9.1(3.1)$ & $9.3(2.2)$ \\
\hline \multicolumn{6}{|l|}{ Late blind } \\
\hline 2.5 & $1.9(0.5)$ & $2.9(0.8)$ & $2.4(0.7)$ & $2.3(0.6)$ & $2.3(0.6)$ \\
\hline 5.1 & $3.6(1.0)$ & $4.7(1.3)$ & $4.3(1.5)$ & $4.1(1.1)$ & $4.2(1.2)$ \\
\hline 7.6 & $5.8(1.9)$ & $6.7(1.9)$ & $6.2(1.9)$ & $6.3(1.9)$ & $6.3(1.8)$ \\
\hline 10.2 & $7.6(2.3)$ & $8.5(2.6)$ & $8.5(2.8)$ & $7.4(2.4)$ & $8.0(2.4)$ \\
\hline \multicolumn{6}{|l|}{ Low vision } \\
\hline 2.5 & $1.8(0.7)$ & $2.9(1.1)$ & $2.5(0.9)$ & $2.6(0.9)$ & $2.5(0.8)$ \\
\hline 5.1 & $3.7(1.3)$ & $4.8(1.7)$ & $4.7(1.7)$ & $4.6(1.4)$ & $4.5(1.4)$ \\
\hline 7.6 & $5.7(1.7)$ & $6.9(2.2)$ & $6.9(2.4)$ & $6.9(2.6)$ & $6.6(2.1)$ \\
\hline 10.2 & $7.6(2.5)$ & $8.8(3.6)$ & $8.1(2.3)$ & $8.5(2.9)$ & $8.2(2.7)$ \\
\hline \multicolumn{6}{|c|}{ Blindfolded sighted (younger subjects) } \\
\hline 2.5 & $2.0(0.5)$ & $3.1(0.5)$ & $2.6(0.6)$ & $2.7(0.7)$ & $2.6(0.4)$ \\
\hline 5.1 & $3.9(0.5)$ & $5.1(1.1)$ & $4.4(0.9)$ & $4.7(0.8)$ & $4.5(0.6)$ \\
\hline 7.6 & $6.3(1.5)$ & $7.2(1.7)$ & $6.9(1.5)$ & $7.0(1.4)$ & $6.8(1.4)$ \\
\hline 10.2 & $8.3(2.4)$ & $8.9(2.3)$ & $8.8(2.0)$ & $9.1(2.0)$ & $8.8(2.0)$ \\
\hline \multicolumn{6}{|c|}{ Blindfolded sighted (older subjects) } \\
\hline 2.5 & $1.9(0.6)$ & $3.9(1.4)$ & $2.5(0.3)$ & $2.9(0.4)$ & $2.8(0.6)$ \\
\hline 5.1 & $4.0(0.8)$ & $5.8(1.4)$ & $4.7(1.2)$ & $5.0(1.1)$ & $4.9(1.0)$ \\
\hline 7.6 & $7.1(1.4)$ & $7.9(1.7)$ & $6.9(1.1)$ & $7.3(0.9)$ & $7.3(1.2)$ \\
\hline 10.2 & $8.8(2.3)$ & $9.6(2.3)$ & $9.0(2.1)$ & $9.4(1.8)$ & $9.2(2.0)$ \\
\hline
\end{tabular}


impression of length, since these lines were judged as longer than the plain lines. There was also a significant main effect of line size $\left(F_{3,108}=368.15, p<0.01\right)$. As expected, a Newman-Keuls test indicated that subjects judged all four line sizes as significantly different from each other.

The main effect of visual status was not significant $(F<1)$, indicating that prior visual experience had no effect on haptic judgments of line size in the Müller-Lyer figure. The main effect of trials was also nonsignificant, as were all interactions (all $p \mathrm{~s}>0.10)$.

The lack of an effect of visual status means that the presence of the Müller-Lyer illusion in touch is not dependent upon visual experience or visual imagery. The congenitally blind subjects showed the same pattern of illusory size distortion as the other subjects. The illusion was if anything stronger in the congenitally blind subjects. Thus, the congenitally blind subjects showed slightly larger differences between their judgments of the wings-in versus wings-out figures. They also showed somewhat less underestimation than the blindfolded-sighted subjects.

One reviewer questioned the appropriateness of the sighted comparison group, since they were much younger than the congenitally blind subjects. Age can influence the impact of illusions, and there is some evidence that gender may influence the magnitude of the illusion as well (Porac et al 1979). According to Coren and Girgus (1978), older individuals may sometimes show weaker responses to illusions. Consequently, an additional group of older sighted subjects $(n=10$, mean age $=48.9$ years; $\mathrm{SD}, 7.2$ years, five males, five females) was tested with the same procedures as in experiment 1 . Five of these older subjects were faculty members and five were staff. An ANOVA on size judgments comparing the younger and older sighted groups revealed a nonsignificant effect of age $(F<1)$. All of the interactions with age failed to reach significance (all $p \mathrm{~s}>0.10$ ). Separate ANOVAs were run that compared these sighted control groups (younger and older) with the congenitally blind subjects to determine if gender influenced the magnitude of the Müller-Lyer illusion, and they both yielded nonsignificant effects of gender (both $F \mathrm{~s}<1$ ). In both analyses, all of the interactions with the variables of gender or visual status were nonsignificant (all $p \mathrm{~s}>0.10$ ). The data for these older sighted subjects were substituted for the younger ones and the ANOVA was rerun. The results were nearly identical to those of the main analyses reported here, and the effect of visual status was nonsignificant $(F<1)$. The presence of the illusion was shown by a highly significant effect of line ending $\left(F_{3,108}=24.0\right.$, $p<0.001)$. All of the interactions with visual status failed to reach significance (all $p \mathrm{~s}>0.40$ ). As in the ANOVA with younger controls, a Newman-Keuls test showed that the wings-in figures were judged as shorter than all the other stimuli and the wings-out stimuli were judged as significantly longer $(p<0.05)$. The plain lines and the lines with vertical endings were not significantly different $(p>0.05)$.

Subjects showed a general underestimation of line size, and it is not clear why this occurred. It is not likely that the use of bimanual exploration, per se, produced this underestimation. The subjects in Heller et al (1999) were able to make precise and accurate size estimates with the use of two hands when feeling wooden squares. In haptic control conditions of that earlier experiment, subjects felt squares with their right hands, and chose comparison squares with their left hands. This issue is taken up again at a later point in this manuscript.

\section{Experiment 2: Texture and length judgments}

It was conceivable that the obtained underestimation in experiment 1 could have derived from the use of raised lines as stimuli. Corsini and Pick (1969) reported that subjects judged rough surfaces as shorter than smooth surfaces. The raised lines in the present experiment felt bumpy and rough, and this may have contributed to 
a general underestimation of perceived length. Consequently, an experiment was conducted that compared size estimates for raised lines with smooth wooden dowels. This experiment was designed to determine if raised lines yield underestimation of the lengths of lines.

\subsection{Method}

3.1.1 Participants. The subjects were twelve blindfolded-sighted undergraduate volunteers (six males, six females). Only strongly right-handed subjects participated. Subjects were identified as right-handed in this experiment if they responded "right hand" to all questions on a questionnaire (derived from Millar 1984) asking which hand they used for the following activities: writing, drawing, throwing a ball, cutting with scissors, using a soup spoon, and brushing teeth.

3.1.2 Stimuli and apparatus. The stimuli were raised lines or $6 \mathrm{~mm}$ thick hardwood dowels with lengths of $2.5,5.1,7.6$, and $10.2 \mathrm{~cm}$. The dowels were sanded so that they were smooth after an application of varnish. The stimuli were oriented horizontally, at the subjects' body midline. The tangible ruler of experiment 1 was placed above the stimuli on a shelf. This permitted the subjects to trace the stimuli with the index finger of one hand and simultaneously manipulate the ruler with the opposite hand.

3.1.3 Design and procedure. A repeated-measures design was used, with the variables being type of line (raised line versus dowel), hand used to feel the stimulus (left versus right), size $(2.5,5.1,7.5,10.2 \mathrm{~cm})$, and trials (2 trials). Half of the subjects began by tracing stimuli with the index finger of their right hand, and half began tracing with their left hands. The opposite hand was used to adjust the tangible ruler for size estimates. Each subject was exposed to two trial blocks for the right or left hand, each of which included the four sizes of lines and dowels. Subsequently, subjects felt the stimuli with the opposite hand. Subjects were told that they could manipulate the ruler in any fashion that they wished, and could alter their judgments as they continued to trace the line or dowel.

\subsection{Results and discussion}

The effect of type of stimulus line was nonsignificant $\left(F_{1,11}=2.0, p=0.19\right)$, as was the effect of hand $(F<1)$. While the effect of size was highly significant $\left(F_{3,33}=199.05\right.$, $p<0.001)$, the effect of trial block failed to reach significance $(F<1)$. All of the two-way and three-way interactions were nonsignificant (all $p \mathrm{~s}>0.15$ ). However, there was a marginally significant four-way interaction $\left(F_{3,33}=2.7, p=0.06\right)$. This marginal interaction derived from a very small component of the total variance in the experiment, and is probably spurious. The raised lines $($ mean $=5.9 \mathrm{~cm}$ ) were judged as slightly longer than the wooden dowels $($ mean $=5.6 \mathrm{~cm}$ ), and so the generalized underestimation of size that was found in experiment 1 cannot be explained in terms of the roughness of the raised lines. There was far less underestimation of raised lines in experiment 2 than in experiment 1, and this point is discussed further at a later point in this paper. If anything, subjects judged the raised lines more accurately than they did the lengths of the dowels. It should be noted that overestimation of size was found with raised lines in the horizontal-vertical illusion, when a pincers posture was used as a response measure for size estimates (Heller et al 1997).

While the effect of hand on length judgments was nonsignificant, this does not mean that use of the right hand to feel the stimuli may not have influenced the expression of the illusion in experiment 1 . The horizontal-vertical illusion may be stronger with the use of the right hand (Heller et al 1993), since the right brain may be more accurate in the processing of spatial information. Tsai reported a stronger illusion with the use of the right hand, but also found that the Müller-Lyer illusion was present when subjects felt stimuli with their left hands (Tsai 1967). 


\section{Experiment 3: The effect of wing angle}

In experiment 3, we examined the effect of wing angle on the Müller-Lyer illusion. In vision, the magnitude of the illusion is affected by wing angle, with a stronger illusion resulting from more acute angles (Coren and Girgus 1978). A variety of explanations have been offered, including a confusion model, namely the idea that it is more difficult to 'see' the ends of the lines given acute wing angles. Thus, image blur strengthens the illusion, but the effect is smaller than the effect of wing angle (page 82). Some comments of the blind subjects in experiment 1 are consistent with the confusion model. A few of them said that they thought that the presence of the wings-out configuration made it easier for them to judge line length, since it made the ends of the lines more distinctive. Note that subjects judged the wings-out figures more accurately with reference to absolute size. Moreover, several blind individuals also spontaneously made statements that suggested that the wings-in figures were misjudged because they "... found it hard to feel the ends of the lines". It is possible that sensory factors were at work, and sensory inhibition and confusion may have impeded perception of the ends of the lines (see Coren and Girgus 1978). Thus, sensory inhibition could impede detection of the ends of the lines in the wings-in stimuli, and this should intensify with smaller angles. For wings-out patterns, confusion about where the horizontal lines end and the wings begin would increase with more acute angles. Thus, it was expected that the magnitude of the Müller-Lyer illusion would increase with more acute included angles.

\subsection{Method}

4.1.1 Participants. The twelve blindfolded-sighted undergraduate volunteers (six males, six females) were experimentally naïve. All were strongly right-handed.

4.1.2 Stimuli and apparatus. The stimuli were similar to those in experiment 1, except that they were limited to wings-in and wings-out figures. The included angles were $30^{\circ}$, $60^{\circ}$, and $120^{\circ}$. As in experiments 1 and 2, the sliding ruler was used for size estimates.

4.1.3 Design and procedure. The experiment was a repeated-measures design, with the variables being wing angle $\left(30^{\circ}, 60^{\circ}, 120^{\circ}\right)$, wing direction (wings-in versus wings-out), size $(2.5,5.1,7.5,10.2 \mathrm{~cm})$, and trials (2 trials). The variable of wing angle was completely counterbalanced over gender. In most respects, the procedure was similar to that of experiment 1 , and subjects felt the tangible raised lines with the index fingers of their right hands.

\subsection{Results and discussion}

The illusion was more robust with the smallest included wing angle (see table 3 ). An analysis of variance revealed a significant effect of wing angle $\left(F_{2,22}=3.6, p<0.05\right)$. An illusion was found, with a highly significant effect of wing direction $\left(F_{1,11}=87.9\right.$, $p<0.001)$. However, the interaction between wing angle and direction was significant as well $\left(F_{2,22}=31.6, p<0.001\right)$. Tests of the simple effects of this interaction showed that the effect of wing angle was present for both levels of wing direction $(p<0.01)$, and the effect of wing direction was significant for all angles (all $p \mathrm{~s}<0.001$ ). The illusion was present throughout, but clearly gained in magnitude as the wing angle

Table 3. Mean size judgments $(\mathrm{cm})$ for the Müller-Lyer illusion for sighted subjects in experiment 3 as a function of figure, size, and wing angle (standard deviations in parentheses).

\begin{tabular}{|c|c|c|c|c|c|c|}
\hline \multirow{2}{*}{$\begin{array}{l}\text { Actual figure } \\
\text { size } / \mathrm{cm}\end{array}$} & \multicolumn{2}{|c|}{ Wing angle $30^{\circ}$} & \multicolumn{2}{|c|}{ Wing angle $60^{\circ}$} & \multicolumn{2}{|c|}{ Wing angle $120^{\circ}$} \\
\hline & wings-in & wings-out & wings-in & wings-out & wings-in & wings-out \\
\hline 2.5 & $1.55(0.85)$ & $3.86(0.87)$ & $1.83(0.63)$ & $3.21(0.64)$ & $2.46(1.03)$ & $2.88(0.71)$ \\
\hline 5.1 & $3.73(0.99)$ & $6.03(1.39)$ & $3.91(0.99)$ & $5.22(1.50)$ & $4.13(1.15)$ & $5.03(1.26)$ \\
\hline 7.6 & $6.15(1.44)$ & $8.56(1.33)$ & $6.23(1.49)$ & $7.30(1.83)$ & $6.63(1.41)$ & $7.56(1.52)$ \\
\hline 10.2 & $7.93(1.70)$ & $10.49(1.66)$ & $7.62(1.80)$ & $8.90(2.40)$ & $8.67(1.88)$ & $9.17(1.70)$ \\
\hline
\end{tabular}


decreased from $120^{\circ}$ (mean wings-in $=5.5 \mathrm{~cm}$, mean wings-out $=6.2 \mathrm{~cm}$ ) to $30^{\circ}$ (mean wings-in $=4.8 \mathrm{~cm}$, mean wings-out $=7.2 \mathrm{~cm}$ ). The outcome of the experiment was consistent with the introspective reports of the blind subjects in experiment 1 about difficulty feeling the ends of the lines for the wings-in figures.

The results of experiment 3 are consistent with confusion models. Subjects may have difficulty discriminating between the horizontal lines and the wings endings that they were told to ignore. Inability to ignore the global size of the stimuli could yield overestimation of the wings-out stimuli compared with plain lines. The present experiments cannot discriminate between an averaging model and some other general confusion models, since both are consistent with an increase in illusion magnitude with more acute angles. An averaging model would assume that subjects perceive the endings of the lines as lying in the middle of an ovoid defined by the wings configuration (see DeLucia 1993). This averaging process would yield underestimation in the wings-in configuration, and overestimation in the wings-out stimuli. On this averaging model, as wing angle diminishes, the center of the wings area moves inward (for wings-in stimuli) or outward (for wings-out figures), leading to progressively shorter or longer judged linear extent.

\section{General discussion}

The present study confirmed the presence of a haptic Müller-Lyer illusion in samples of congenitally blind, late-blind, and low-vision subjects. The presence of the illusion was not dependent upon visual experience or visual imagery, since the illusion was found in all groups of subjects, and the effect of visual experience was nonsignificant. Moreover, the illusion seemed somewhat stronger in the congenitally blind subjects, and this could not be due to the operation of visual imagery.

It is probable that the haptic illusion reflects the operation of multiple causal factors. The results of experiment 3 are consistent with a confusion model of the Müller-Lyer illusion (see Coren and Girgus 1978). Subjects reported that they had difficulty judging where the ends of the lines were in the wings-in figures, and this was supported by the results of experiment 3 . This difficulty could have derived from simple confusion, or sensory inhibition, or perhaps both factors. Note that the results of experiment 1 can not be explained solely in terms of global responding (Coren and Girgus 1978). The global-responding hypothesis suggests that subjects respond to the overall size of the stimuli. However, this would not explain smaller size estimates for the wings-in stimuli as compared with lines with plain ends in experiment 1 . The underestimation of the wings-in stimuli is explainable in terms of a confusion model, or an averaging model (a form of confusion model), and this is supported by the results of experiment 3 . Whatever the appropriate explanation of the Müller-Lyer illusion, the haptic illusion was more powerful than one often finds for visual stimuli (eg DeLucia et al 1994).

One reviewer wondered if the confusion model was consistent with the generalized underestimation of all lines found in experiment 1 . The confusion model can certainly explain overestimation of wings-out figures compared with plain lines, or lines with vertical ends. In addition, the model is consistent with illusory underestimation of the wings-in stimuli compared with plain lines, or lines with vertical ends in the first experiment. The problem here is to explain the generalized bias that yielded underestimation. The following comments are speculative. One possibility is that the generalized underestimation is linked to the response measure. The horizontal tangible ruler was elevated in space upon a shelf, so as to permit placement of the illusory stimuli beneath it. The elevation may have contributed to subject bias, so that judged extent could vary with elevation. Thus, it is possible that the response judgment could vary with evaluation in space.

A more likely explanation is that subjects were affected by the changes in the stimulus configurations in the first experiment. The procedure entailed repeated 
measures on stimulus configurations, so that subjects had a number of trials in which they experienced wings-in and wings-out stimuli or plain lines (or lines with vertical ends). The change from one type of line to another may have yielded biased judgments. Consistent with this explanation is that there was less underestimation of line length in experiment 3 (see table 3). It was interesting that subjects showed generalized overestimation of the wings-out lines when the wing angle was $30^{\circ}$. Thus, the obtained underestimation that was found was probably related to the greater angles of the wings and the use of repeated measures on type of line in experiment 1 . Note that it would not have been possible to obtain independent groups of blind subjects for the variable of type of line ending. Blind subjects are small in number, and so it is not possible to select large samples, or to control for such variables as gender or educational level.

The results of experiment 2 are consistent with this repeated-measures explanation of the obtained generalized underestimation in experiment 1. There was far less underestimation of the plain raised lines $($ mean $=5.9 \mathrm{~cm})$ in experiment 2 than in experiment 1 , where the lines were judged as smaller (mean $=5.54 \mathrm{~cm}$ ). Thus, exposure to the wings figures may have altered the subjects' mean responses to the plain lines in experiment 1 . There was relatively little bias in the subjects' judgments of the raised lines in experiment 2, since the mean of the objective line lengths was $6.35 \mathrm{~cm}$.

The present results suggest that the Müller-Lyer illusion is not dependent upon visual imagery in congenitally blind subjects using touch, but, of course, this says nothing about the causes of illusory misperception in vision, or in blindfolded-sighted subjects using touch. Illusions could derive from different causes in vision and touch, and it is a mistake to attempt simple generalizations from one sense to the other. For example, it is not clear whether or not the Poggendorff illusion exists in touch (Wenderoth and Alais 1990). The visual Müller-Lyer illusion could depend upon mistaken judgments about the relative distance of lines that represent intersection of planes. Therefore, the causes of misperception in the sense of touch could derive from different factors than vision, yet could still yield similar distortions of space. Moreover, sighted subjects in the present experiments could use size-constancy scaling, even if the congenitally blind subjects do not. Thus, sighted subjects may visualize the patterns that they feel, and vision can alter haptic perception via the application of size-constancy scaling (eg Walker 1971).

Sighted subjects appear to prefer tracing with the index finger when feeling raisedline drawings (Symmons and Green 2000). However, many of the blind subjects in the present study objected to being restricted to the use of one finger for tracing. Many said that this exploration method was not natural, and one person stated that he thought that it was like asking a sighted person to view the world with one eye. One blind subject, a rehabilitation teacher of blind children, said that he normally taught children to judge size with the use of multiple fingers to grasp extents. He thought that the use of one finger would degrade performance when making size estimates. This issue is the subject of future research, but it is possible that tracing influenced, or perhaps induced the illusion in experiments 1 and 3 reported here.

It should be noted that the present results are relevant to the design of effective maps and other graphical displays for visually impaired individuals. Intersecting lines and line endings yield altered perception of length, and it is not appropriate to assume that one may generalize directly from vision to touch. The intersecting lines in the wings-in version of the Müller-Lyer illusion could yield sensory inhibition in touch, and this effect could be stronger than in vision. Subjects in the present experiments judged lines with or without vertical endings as shorter than the wings-out figures, and similar distortion of perceived extent could be found in more complex displays, namely tangible maps. Maps depict metric distance relations. A generalized underestimation of extent might not represent serious problems with estimates of trajectories for route finding, if the underestimation were uniform. However, errors that vary as a function of the angles of intersecting 
lines could yield substantial errors when subjects predict trajectories. Moreover, nonsystematic underestimation of extent could yield substantial errors when individuals attempt to translate spatial information acquired from maps to real-life mobility in a natural environment. In addition, a generalized underestimation of extent could impair an individual's ability to make use of scale information in maps, and this has implications for map design. This is a subject that is worthy of future empirical investigation.

Acknowledgments. Preparation of this report and the research were supported by NIH Grant RO1-EY 12040. Faith Heller provided helpful comments on an earlier version of this manuscript.

\section{References}

Axelrod S, Cohen L D, 1961 "Senescence and embedded figure performance in vision and touch" Perceptual and Motor Skills $12283-288$

Casla M, Blanco F, Travieso D, 1999 "Haptic perception of geometric illusions by persons who are totally congenitally blind" Journal of Visual Impairment and Blindness $93583-588$

Coren S, Girgus J S, 1978 Seeing is Deceiving: The Psychology of Visual Illusions (Hillsdale, NJ: Lawrence Erlbaum Associates)

Corsini D, Pick H L, 1969 "The effect of texture on tactually perceived length" Perception \& Psychophysics $5352-356$

DeLucia P R, 1993 "A quantitative analysis of illusion magnitude predicted by several averaging theories of the Müller-Lyer illusion" Perception \& Psychophysics $53498-504$

DeLucia P R, Longmire S P, Kennish J, 1994 "Diamond-winged variants of the Müller-Lyer figure: A test of Virsu's (1971) centroid theory" Perception \& Psychophysics 55 287-295

Dewar R E, 1967 "Sex differences in the magnitude and practice decrement of the Müller-Lyer illusion" Psychonomic Science $9345-346$

Fisher G H, 1970 "An experimental and theoretical appraisal of the perspective and sizeconstancy theories of illusions" Quarterly Journal of Experimental Psychology 22 631-652

Gregory R L, 1963 "Distortion of visual space as inappropriate constancy scaling" Nature 199 $678-680$

Hatwell Y, 1960 "Étude de quelques illusions géométriques tactiles chez les aveugles" L'Année Psychologique $6011-27$

Heller M A (Ed.), 2000a Touch, Representation and Blindness Debates in Psychology Series (Oxford: Oxford University Press)

Heller M A, 2000b "Haptic perceptual illusions", in Toucher pour Connaitre Eds Y Hatwell, A Streri, E Gentaz (Paris: Presses Universitaires de France) pp $163-174$

Heller M A, Brackett D D, Scroggs E, Allen A C, Green S, 2001 "Haptic perception of the horizontal by blind and low-vision individuals" Perception $30601-610$

Heller M A, Calcaterra J A, Burson L L, Green S L, 1997 "The tactual horizontal-vertical illusion depends on radial motion of the entire arm" Perception \& Psychophysics 59 1297-1311

Heller M A, Calcaterra J A, Green S L, Brown L, 1999 "Intersensory conflict between vision and touch: The response modality dominates when precise, attention-riveting judgments are required" Perception \& Psychophysics $611384-1398$

Heller M A, Joyner T D, Dan-Fodio H, 1993 "Laterality effects in the haptic horizontal-vertical illusion" Bulletin of the Psychonomic Society $31440-442$

Heller M A, Schiff W (Eds), 1991 The Psychology of Touch (Hillsdale, NJ: Lawrence Erlbaum Associates)

Kennedy J M, 1997 "How the blind draw" Scientific American 276(1) 76-81

Kennedy J M, Gabias P, Nichols A, 1991 "Tactile pictures", in The Psychology of Touch Eds M A Heller, W Schiff (Hillsdale, NJ: Lawrence Erlbaum Associates) pp 263-300

Millar S, 1984 "Is there a 'best hand' for braille?" Cortex $2075-87$

Porac C, Coren S, Girgus J S, Verde M, 1979 "Visual-geometric illusions: unisex phenomena" Perception $8401-412$

Revesz G, 1950 The Psychology and Art of the Blind (London: Longmans Green)

Symmons M, Green B, 2000 "Raised line drawings are spontaneously explored with a single finger" Perception $29621-626$

Tsai L S, 1967 "Müller-Lyer illusion by the blind" Perceptual and Motor Skills 25641 -644

Walker J T, 1971 "Visual capture in visual illusions" Perception \& Psychophysics 1071 - 74

Wenderoth P, Alais D, 1990 "Lack of evidence for a tactual Poggendorff illusion" Perception \& Psychophysics $\mathbf{4 8} 234-242$ 